\title{
Genetic Algorithm for Constrained Optimization with Stepwise Approach in Search Interval Selection of Variables
}

\author{
Shekhar L. Pandharipande \\ Associate Professor, \\ Department of Chemical \\ Engineering, LIT, RTMNU, \\ Nagpur, India
}

\author{
Aarti R. Deshmukh \\ M.Tech, Department of \\ Chemical Engineering, LIT, \\ RTMNU, Nagpur, India
}

\author{
Rohit P. Kalnake \\ M.Tech, Department of \\ Chemical Engineering, LIT, \\ RTMNU, Nagpur, India
}

\begin{abstract}
Genetic algorithms are evolutionary algorithms that are well suited in searching global solution to varied nature of optimization problems. The inspirations in developing GA are derived from working principle of natural genetics. The operators such as reproduction, crossover \& mutation are employed similar to natural genetics. These steps involved elements of probability that make search for optimal solution random making GA stochastic \& nondeterministic. There are several initiatives made by researcher in improving the search direction \& making it more definitive. Present work aims at suggesting a novel stepwise approach in search interval selection of variables using Genetic algorithm. Three nonlinear optimization problems are selected for numerical experimentation with comparative studies of respective solution using conventional methods and GA techniques with $\&$ without stepwise approach.

Test run are conducted with constant GA parameters and the best function values for five consecutive run are tabulated. Corresponding values of variables decide the search interval selection criteria for step 1 . Five elite-GA ${ }^{\odot}$ run are conducted for step 1 for newly defined search interval of variables. The corresponding values of the variables obtained as in step 1 decide the search interval selection for step 2. Number of steps continues till no further improvement in the function values is obtained. Based on the result of the present work it can be concluded that the optimal values obtained for all the three test problems evaluated using the stepwise approach are better than those obtained using GA without stepwise approach \& conventional techniques.

The present work is demonstrative \& it is felt necessary to substantiate the claim by extending this stepwise search interval approach of GA in selection of variables to other problems of optimization.
\end{abstract}

\section{Keywords}

Genetic algorithm; non-linear optimization problems; stepwise approach; search interval selection.

\section{INTRODUCTION}

The optimization problems are characterized by objective functions with or without constraints. In constrained optimization there are possibilities of combinations of linear $\&$ non-linear objective functions with linear \& non-linear constraints. There are various methods reported, which address to these optimization problems. Each method has its limitations and can be applied to certain situations selectively. In addition to this these techniques are found to be inefficient and often arrive at relative optimum that is closest to the starting point. Genetic Algorithm has uniqueness amongst methods of optimization and has emerged as a universal tool that can be can be applied to the various problems of optimization. Where the objective function and constraints are well defined and GA reached the global optimum with high probability[1-3].

\section{GENETIC ALGORITHM}

Genetic Algorithms (GAs) come under the category of evolutionary algorithms with working principle based on the mechanics of natural genetics. The basic objective in natural genetics is the retention of the fit genes \& discard of the redundant. New generations created by manipulating the genetic code using the tools such as selection, crossover \& mutation. GA also works in similar manner with the objective to search appropriate solution for the problems involving either minimization or maximization of the objective function. GA use similar tools as selection, crossover \& mutation applied to a population of binary strings generated randomly. In every generation, a new set of artificial species or strings is created using bits and pieces of the fittest among old; an occasional new part may be tried for good measure. Genetic algorithms are proven to yield robust search in complex spaces[4].

Many methods, techniques $\&$ algorithms have been developed over the decades that are reported in books[1-3] \& journals for the optimization problems that are originating from the day to day life \& different disciplines including engineering operations[4]. Genetic Algorithm differs from the other optimization and search procedures in following ways:

- The search is carried over a population generated randomly for combination of variables of a possible solution by manipulating their binary coded version

- GA can be seen as universal technique that can address to several types of optimization problems \& handle nonlinear, complex and noisy functions.

- GA performs global search \& very often arrive at or near the global optimum.

- GA does not put prerequisites on function such as smoothness, derivability, and continuity.

\subsection{Working principle of GAs:}

GA is well suited for both maximization and minimization of an objective function. The fitness function essentially measures the "goodness" or "quality" of each candidate solution and its magnitude is proportional the fitness of objective function.

A population of genes or binary coded numbers representing the respective variables involved in an objective function is 
randomly generated. These are arranged to form chromosomes or strings to represent the possible combinations of variables for the solution. The fitness evaluation of each chromosome or the candidate is based on the relative values of their objective function. The stronger strings are selected $\&$ the weaker discarded. A new population is generated by combining the strings by swapping their respective parts in a pair using the crossover tool. The mutation is carried on few of the bits of the string population by changing their values from 0 into 1 and vice versa; as the case may be. The fitness test on new generation is carried out $\&$ the process is repeated for several generations. The solutions represented by such a new generation chromosomes are likely to be better in terms of their fitness values when compared with those represented by the chromosomes in the current population[4]

The steps involved in developing genetic algorithm are as follows:

\subsubsection{Initialization}

It is the first step in which a population of suitable pop size of binary strings of suitable chromosome length is created. All the strings are evaluated for their fitness values using specified fitness function. The objective function is interpreted in the light minimization and maximization \& becomes the fitness function.

\subsubsection{Reproduction}

It involves selection of the chromosomes from the current population to form a mating pool for the next generation production. The selection procedure is stochastic wherein fitter chromosomes have a better chance of getting selected.

\subsubsection{Crossover}

This step results in creating two offspring chromosomes from each parent pair selected randomly. The two parent chromosomes selected are cut at same randomly selected crossover points to obtain two sub-strings per parent string. The second sub-string is then mutually exchanged and combined with the respective first sub-string to form two offspring chromosomes.

\subsubsection{Mutation}

Among the members of the population generated, randomly as many elements of the offspring are mutated with probability equal to $P_{\text {mut. }}$ This is usually very small $\&$ avoids creation of entirely different search sub-spaces. This prevents the GA search from becoming absolutely random.

The new population undergoes the fitness test. The steps are repeated \& finally, the values of the variables obtained hereby represent the optimized solution.

In one generation crossover and mutation operators are applied only once. Thus generation means how many times the crossover and mutation must operate on the population. Generation is synonymous to iteration.

Unconstrained \& constrained are the two broad classifications in optimization. Several optimization techniques reported to solve unconstrained problems[1]. The more complex situation are constrained optimization involving non-linear function with linear \& non linear constraints[5-7] \& researchers are engaged in suggesting \& improving techniques in solving them.
GAs are stochastic search algorithm and can be employed to multiobjective[8-9] \& both unconstrained[10-11]-constrained problems[13-17]. Several papers have been reported using GA techniques to solve test problems \& problems representing engineering operations[18-24].

GA is a random search method with an element of uncertainty in moving the search direction towards global optimal value. This limitation of GA in handling problems with multi-modal minima or maxima has drawn attention of researchers[25-26]. Several initiatives in incorporating features in modification of GA have been reported[27-30].

Present work proposes stepwise approach in search interval selection of variables in making GA search more definitive towards reaching the optimal value. It also aims at the utility \& effectiveness study of new step wise approach to Genetic Algorithm in solving non linear optimization problems with linear constraints.

\section{NUMERICAL EXPERIMENTS}

Three types of test objective functions have been considered for numerical experimentation \& elite- $\mathrm{GA}^{\odot}$ is used for obtaining GA solutions[31]. Table 1 gives the values of the GA parameter like pop size, crossover, mutation \& number of iterations that are kept constant for the test \& step run of elite$\mathrm{GA}^{\odot}$ for the numerical experiment. Each step consists of 5 run $\&$ each run has 40 iterations. A comparative studies of the optimal values obtained using GA with \& without step wise approach with different techniques is carried out.

Table 1. Value of constant of GA parameters for all elite-

\begin{tabular}{|c|c|c|c|}
\hline $\begin{array}{l}\text { Populati } \\
\text { on size } \\
\text { Pop size }\end{array}$ & $\begin{array}{c}\text { Crossover } \\
\text { Probability } \\
P_{\text {P }}(\%)\end{array}$ & $\begin{array}{c}\text { Mutation } \\
\text { Probability } \\
\mathbf{P}_{\text {pution }}\end{array}$ & $\begin{array}{c}\text { Number of } \\
\text { Iterations } \\
\mathrm{N}_{\text {Iteration }}\end{array}$ \\
\hline 20 & 20 & 0.001 & 40 \\
\hline
\end{tabular}

\subsection{Non-linear objective function with linear inequality constraints}

\subsubsection{Function:}

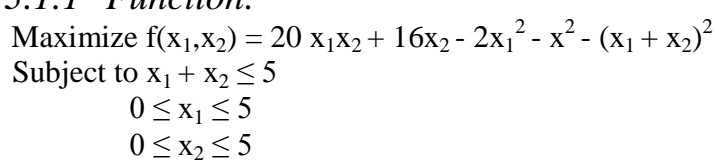

Conventional technique

The objective function 3.1.1 can be solved using Penalty function method that includes approximation of linear programming[32]. The details are reported in literature.

Genetic Algorithm technique

The present work optimizes the function 3.1.1 in stepwise manner using elite-GA ${ }^{\odot}$. The snapshot of the elite-GA ${ }^{\odot}$ run mode for function 3.1.1 is shown in Fig. 1 .

Table 2 gives the details of the best values of the function with the corresponding values of the search variables obtained during consecutive five test run. Based on these values of the objective function obtained the search interval range for the variables is set for carrying out the step 1 run. The values of the search variables set $\&$ the best values of the function obtained during the five consecutive run are listed in Table 3. This procedure is followed for the remaining steps. 
Table 3 gives the details of search interval set for variables \& best values obtained for consecutive five run for steps 1 to 5 .
Table 4 gives the details of the best values of the objective function obtained for consecutive 25 run of GA with similar parameters without stepwise approach.

Table 2. Details of elite-GA ${ }^{\oplus}$ test run for function 3.1.1

\begin{tabular}{ccccccccc}
\hline \multirow{2}{*}{ Run } & \multicolumn{2}{c}{ Limits of $\mathbf{x}_{\mathbf{1}}$} & \multicolumn{2}{c}{ Limits of $\mathbf{x}_{\mathbf{2}}$} & Best & $\mathbf{x}_{\mathbf{1}}$ & $\mathbf{x}_{\mathbf{2}}$ \\
\cline { 2 - 5 } & Lower & Upper & Lower & Upper & & $\mathbf{f}\left(\mathbf{x}_{\mathbf{1}}, \mathbf{x}_{\mathbf{2}}\right)$ & \multicolumn{2}{c}{ Best value } \\
\hline 1 & 1.0 & 5 & 1.0 & 5 & 42.340 & 3.150 & 1.273 \\
2 & 1.0 & 5 & 1.0 & 5 & 44.516 & 1.538 & 3.345 \\
3 & 1.0 & 5 & 1.0 & 5 & 44.825 & 1.785 & 2.545 \\
4 & 1.0 & 5 & 1.0 & 5 & 44.496 & 2.812 & 1.734 \\
5 & 1.0 & 5 & 1.0 & 5 & 45.837 & 2.032 & 2.648 \\
\hline
\end{tabular}

Table 3. Search interval set for variables \& best values obtained for consecutive five run for step 1 to 5

\begin{tabular}{|c|c|c|c|c|c|c|c|c|c|}
\hline \multirow[t]{2}{*}{1} & \multirow[t]{2}{*}{ Steps } & \multirow[t]{2}{*}{ Run } & \multicolumn{2}{|c|}{ Limits of $x_{1}$} & \multicolumn{2}{|c|}{ Limits of $x_{2}$} & \multirow{2}{*}{$\begin{array}{c}\text { Best } \\
\mathbf{f}\left(\mathbf{x}_{1}, \mathbf{x}_{2}\right)\end{array}$} & \multirow{2}{*}{\multicolumn{2}{|c|}{$\begin{array}{l}\mathrm{x}_{1} \quad \mathrm{x}_{2} \\
\text { Best value }\end{array}$}} \\
\hline & & & Lower & Upper & Lower & Upper & & & \\
\hline 1 & Step 1 & 1 & 1.0 & 3.5 & 1.0 & 3.5 & 42.697 & 3.066 & 1.328 \\
\hline 2 & & 2 & 1.0 & 3.5 & 1.0 & 3.5 & 46.003 & 2.571 & 2.312 \\
\hline 3 & & 3 & 1.0 & 3.5 & 1.0 & 3.5 & 44.503 & 2.768 & 1.733 \\
\hline 4 & & 4 & 1.0 & 3.5 & 1.0 & 3.5 & 46.283 & 2.248 & 2.704 \\
\hline 5 & & 5 & 1.0 & 3.5 & 1.0 & 3.5 & 45.125 & 1.960 & 2.391 \\
\hline 6 & Step 2 & 1 & 2.1 & 2.8 & 2.1 & 2.8 & 46.262 & 2.232 & 2.697 \\
\hline 7 & & 2 & 2.1 & 2.8 & 2.1 & 2.8 & 46.178 & 2.136 & 2.776 \\
\hline 8 & & 3 & 2.1 & 2.8 & 2.1 & 2.8 & 46.236 & 2.237 & 2.660 \\
\hline 9 & & 4 & 2.1 & 2.8 & 2.1 & 2.8 & 46.165 & 2.189 & 2.657 \\
\hline 10 & & 5 & 2.1 & 2.8 & 2.1 & 2.8 & 46.234 & 2.485 & 2.485 \\
\hline 11 & Step 3 & 1 & 2.2 & 2.7 & 2.2 & 2.7 & 46.287 & 2.282 & 2.661 \\
\hline 12 & & 2 & 2.2 & 2.7 & 2.2 & 2.7 & 46.214 & 2.470 & 2.470 \\
\hline 13 & & 3 & 2.2 & 2.7 & 2.2 & 2.7 & 46.306 & 2.299 & 2.665 \\
\hline 14 & & 4 & 2.2 & 2.7 & 2.2 & 2.7 & 45.930 & 2.414 & 2.308 \\
\hline 15 & & 5 & 2.2 & 2.7 & 2.2 & 2.7 & 46.193 & 2.421 & 2.469 \\
\hline 16 & Step 4 & 1 & 2.2 & 2.3 & 2.5 & 2.7 & 46.294 & 2.297 & 2.651 \\
\hline 17 & & 2 & 2.2 & 2.3 & 2.5 & 2.7 & 46.271 & 2.286 & 2.637 \\
\hline 18 & & 3 & 2.2 & 2.3 & 2.5 & 2.7 & 46.232 & 2.650 & 2.621 \\
\hline 19 & & 4 & 2.2 & 2.3 & 2.5 & 2.7 & 46.274 & 2.280 & 2.641 \\
\hline 20 & & 5 & 2.2 & 2.3 & 2.5 & 2.7 & 46.277 & 2.285 & 2.644 \\
\hline 21 & Step 5 & 1 & 2.28 & 2.3 & 2.65 & 2.68 & 46.297 & 2.297 & 2.656 \\
\hline 22 & & 2 & 2.28 & 2.3 & 2.65 & 2.68 & 46.309 & 2.296 & 2.673 \\
\hline 23 & & 3 & 2.28 & 2.3 & 2.65 & 2.68 & 46.306 & 2.298 & 2.666 \\
\hline 24 & & 4 & 2.28 & 2.3 & 2.65 & 2.68 & 46.308 & 2.296 & 2.671 \\
\hline 25 & & 5 & 2.28 & 2.3 & 2.65 & 2.68 & 46.296 & 2.281 & 2.674 \\
\hline
\end{tabular}

Table 4. Details of best values of objective function obtained for 25 consecutive run

\begin{tabular}{cccccc}
\hline $\begin{array}{c}\text { Sr. } \\
\text { No. }\end{array}$ & Run & $\mathbf{f}\left(\mathbf{x}_{\mathbf{1}}, \mathbf{x}_{\mathbf{2}}\right)$ & $\begin{array}{c}\text { Sr. } \\
\text { No. }\end{array}$ & Run & $\mathbf{f}\left(\mathbf{x}_{\mathbf{1}}, \mathbf{x}_{\mathbf{2}}\right)$ \\
\hline 1 & 1 & 42.697 & 14 & 14 & 45.789 \\
2 & 2 & 44.516 & 15 & 15 & 45.298 \\
3 & 3 & 44.825 & 16 & 16 & 32.576 \\
4 & 4 & 44.496 & 17 & 17 & 44.474 \\
5 & 5 & 45.837 & 18 & 18 & 42.476 \\
6 & 6 & 45.136 & 19 & 19 & 36.140 \\
7 & 7 & 37.980 & 20 & 20 & 36.815 \\
8 & 8 & 45.425 & 21 & 21 & 45.671 \\
9 & 9 & 44.465 & 22 & 22 & 43.574 \\
10 & 10 & $\mathbf{4 5 . 9 3 8}$ & 23 & 23 & 41.696 \\
11 & 11 & 34.411 & 24 & 24 & 45.424 \\
12 & 12 & 33.854 & 25 & 25 & 42.686 \\
13 & 13 & 44.800 & & & \\
\hline
\end{tabular}




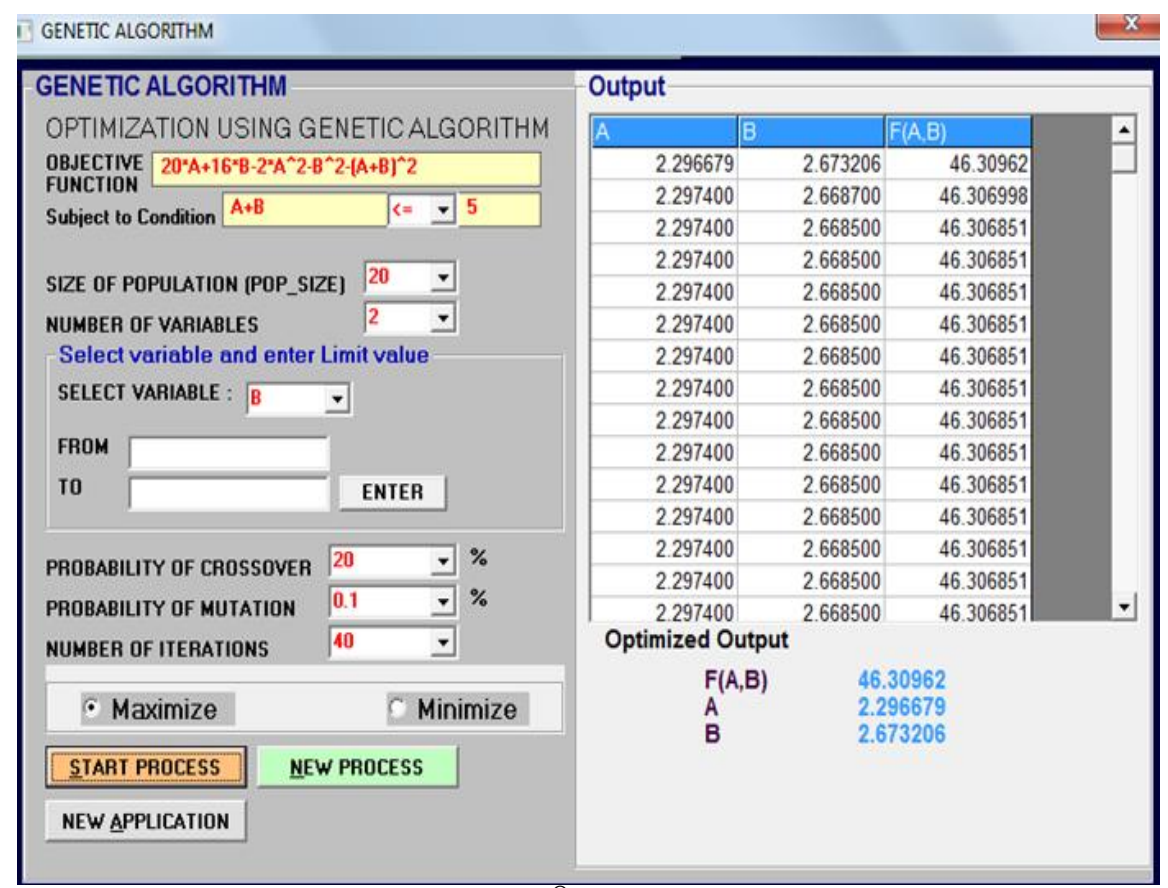

Fig 1: Snapshot of elite-GA ${ }^{\odot}$ in run mode for function 3.1.1

Figs. $2 \& 3$ show graphs plotted between the best value of function obtained for 25 run of elite-GA ${ }^{\odot}$ with \& without stepwise approach respectively.

As can be seen from the nature of these graphs the stepwise approach in search interval selection results in directing the search towards optimal value more definitely.

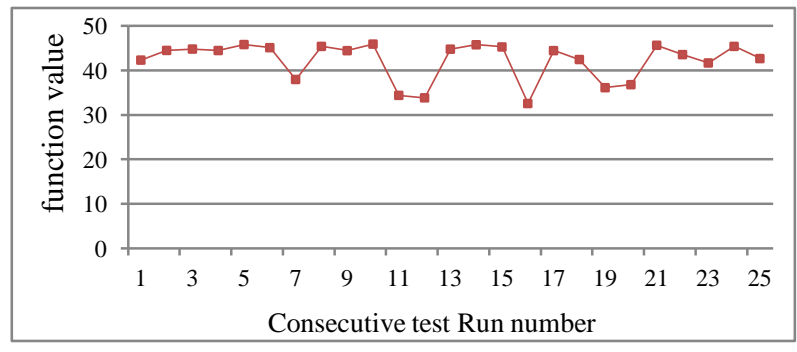

Fig 2: Values of objective function for 25 consecutive run without step wise approach

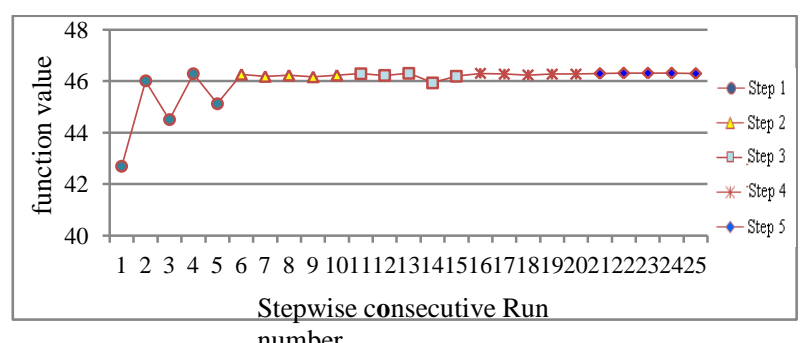

Fig 3: Values of objective function for five consecutive run for each step with stepwise approach

\subsubsection{Results and Discussion}

The objective function discussed in this part of the present work has been solved by Penalty function Constraint Optimization method \& is reported in the literature. The comparison between the global values of the objective function obtained using Penalty function method \& GA with and without stepwise approach is given in Table $5 \&$ Fig 4 depicts the same. The \% deviation in the optimal values obtained using GA technique with stepwise approach is of the order of $0.045 \%$ compared with the global value obtained using conventional technique. Thus these optimal solution obtained using GA technique with stepwise approach is acceptable.

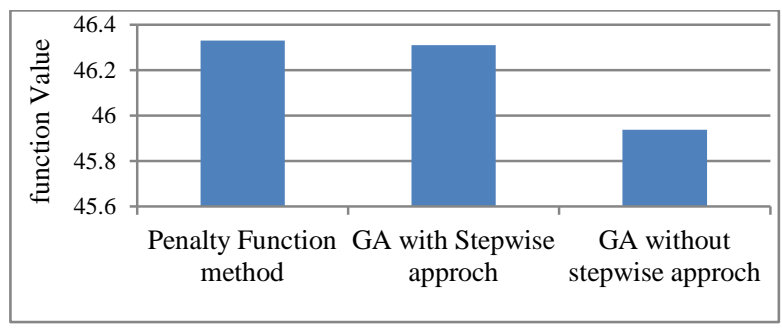

Fig 4: Comparison between global values of function 3.1.1 for conventional and GA with \& without stepwise approach

Table 5. Comparison of optimum results obtained by using penalty function method and GA

\begin{tabular}{cccc}
\hline $\begin{array}{c}\text { Maximum } \\
\text { value of } \\
\text { function }\end{array}$ & $\begin{array}{c}\text { Penalty } \\
\text { function } \\
\text { Method }\end{array}$ & $\begin{array}{c}\text { GA With } \\
\text { stepwise } \\
\text { approach }\end{array}$ & $\begin{array}{c}\text { GA without } \\
\text { stepwise } \\
\text { approach }\end{array}$ \\
\hline $\mathrm{f}\left(\mathrm{x}_{1}, \mathrm{x}_{2}\right)$ & 46.333 & 46.309 & 45.938 \\
\multicolumn{2}{c}{ Search variables: } & & \\
$\mathrm{x}_{1}$ & 2.333 & 2.296 & 2.514 \\
$\mathrm{x}_{2}$ & 2.666 & 2.673 & 2.279 \\
\hline
\end{tabular}

\subsubsection{Function:}

Maximize $\mathrm{f}\left(\mathrm{x}_{1}, \mathrm{x}_{2}\right)=5 \mathrm{x}_{1}-\mathrm{x}_{2}^{2}+8 \mathrm{x}_{2}-2 \mathrm{x}_{2}^{2}$

Subject to $3 \mathrm{x}_{1}+2 \mathrm{x}_{2} \leq 6$

$$
\begin{aligned}
& 0 \leq \mathrm{x}_{1} \leq 2 \\
& 0 \leq \mathrm{x}_{2} \leq 3
\end{aligned}
$$

Conventional technique

The objective function has been solved by Frank-Wolfe algorithm. The details are reported in the literature[2]. 
Genetic Algorithm technique

The present work optimizes the function in stepwise manner and elite-GA ${ }^{\odot}$ is used for this purpose. The snapshot of GA in run mode for function 3.1.2 is shown in Fig. 5.

Table 6 gives the details of the best values of the function with the corresponding values of the search variables obtained during consecutive five test run. Based on the values of the objective function obtained the search interval range for the variables is set for carrying out the step 1 run. The values of the search variables set $\&$ the best values of the function obtained during the five consecutive run of steps 1-8 are listed in Table 7.

Table 6. Details of elite-GA ${ }^{\oplus}$ test run for function 3.1.2

\begin{tabular}{cccccccc}
\hline \multirow{2}{*}{ Run } & \multicolumn{2}{c}{ Limits of $\mathbf{x}_{\mathbf{1}}$} & \multicolumn{2}{c}{ Limits of $\mathbf{x}_{\mathbf{2}}$} & Best $\mathbf{f}\left(\mathbf{x}_{\mathbf{1}}, \mathbf{x}_{\mathbf{2}}\right)$ & $\mathbf{x}_{\mathbf{1}}$ & $\mathbf{x}_{\mathbf{2}}$ \\
\cline { 2 - 4 } & Lower & Upper & Lower & Upper & & \multicolumn{2}{c}{ Best value } \\
\hline 1 & 0 & 2 & 0 & 3 & 8.421 & 0.0859 & 1.9870 \\
2 & 0 & 2 & 0 & 3 & 8.769 & 0.1614 & 2.0752 \\
3 & 0 & 2 & 0 & 3 & 6.734 & 1.3276 & 0.2476 \\
4 & 0 & 2 & 0 & 3 & 11.105 & 1.0888 & 1.2407 \\
5 & 0 & 2 & 0 & 3 & 8.554 & 1.0909 & 0.6380 \\
\hline
\end{tabular}

Table 7. Search interval set for variables \& best values obtained for consecutive five run for step 1 to 8

\begin{tabular}{|c|c|c|c|c|c|c|c|c|c|}
\hline \multirow{2}{*}{$\begin{array}{l}\text { Sr. } \\
\text { No. }\end{array}$} & \multirow[t]{2}{*}{ Steps } & \multirow[t]{2}{*}{ Run } & \multicolumn{2}{|c|}{ Limits of $x_{1}$} & \multicolumn{2}{|c|}{ Limits of $x_{2}$} & \multirow{2}{*}{$\begin{array}{c}\text { Best } \\
\mathbf{f}\left(\mathbf{x}_{1}, \mathbf{x}_{2}\right)\end{array}$} & \multirow{2}{*}{\multicolumn{2}{|c|}{$\begin{array}{c}\mathbf{x}_{1} \quad \mathbf{x}_{\mathbf{2}} \\
\text { Best value }\end{array}$}} \\
\hline & & & Lower & Upper & Lower & Upper & & & \\
\hline 1 & Step 1 & 1 & 0 & 1 & 1 & 2 & 11.144 & 0.7751 & 1.745 \\
\hline 2 & & 2 & 0 & 1 & 1 & 2 & 9.662 & 0.5797 & 1.329 \\
\hline 3 & & 3 & 0 & 1 & 1 & 2 & 10.518 & 0.5936 & 1.779 \\
\hline 4 & & 4 & 0 & 1 & 1 & 2 & 11.077 & 0.7746 & 1.686 \\
\hline 5 & & 5 & 0 & 1 & 1 & 2 & 10.288 & 0.5961 & 1.589 \\
\hline 6 & Step 2 & 1 & 0.5 & 1 & 1.5 & 2 & 11.223 & 0.7819 & 1.807 \\
\hline 7 & & 2 & 0.5 & 1 & 1.5 & 2 & 11.156 & 0.8693 & 1.534 \\
\hline 8 & & 3 & 0.5 & 1 & 1.5 & 2 & 11.466 & 0.9857 & 1.504 \\
\hline 9 & & 4 & 0.5 & 1 & 1.5 & 2 & 11.077 & 0.7887 & 1.650 \\
\hline 10 & & 5 & 0.5 & 1 & 1.5 & 2 & 11.421 & 0.8944 & 1.645 \\
\hline 11 & Step 3 & 1 & 0.7 & 1 & 1.5 & 1.8 & 11.386 & 0.9515 & 1.517 \\
\hline 12 & & 2 & 0.7 & 1 & 1.5 & 1.8 & 11.254 & 0.8730 & 1.582 \\
\hline 13 & & 3 & 0.7 & 1 & 1.5 & 1.8 & 11.135 & 0.7879 & 1.687 \\
\hline 14 & & 4 & 0.7 & 1 & 1.5 & 1.8 & 11.135 & 0.8161 & 1.753 \\
\hline 15 & & 5 & 0.7 & 1 & 1.5 & 1.8 & 11.124 & 0.8254 & 1.598 \\
\hline 16 & Step 4 & 1 & 0.8 & 1 & 1.5 & 1.8 & 11.450 & 0.9166 & 1.617 \\
\hline 17 & & 2 & 0.8 & 1 & 1.5 & 1.8 & 11.369 & 0.9303 & 1.543 \\
\hline 18 & & 3 & 0.8 & 1 & 1.5 & 1.8 & 11.276 & 0.8434 & 1.661 \\
\hline 19 & & 4 & 0.8 & 1 & 1.5 & 1.8 & 11.225 & 0.8338 & 1.647 \\
\hline 20 & & 5 & 0.8 & 1 & 1.5 & 1.8 & 11.361 & 0.8874 & 1.620 \\
\hline 21 & Step 5 & 1 & 0.9 & 1 & 1.4 & 1.6 & 11.490 & 0.9760 & 1.532 \\
\hline 22 & & 2 & 0.9 & 1 & 1.4 & 1.6 & 11.443 & 0.9829 & 1.497 \\
\hline 23 & & 3 & 0.9 & 1 & 1.4 & 1.6 & 11.346 & 0.9815 & 1.453 \\
\hline 24 & & 4 & 0.9 & 1 & 1.4 & 1.6 & 11.431 & 0.9412 & 1.564 \\
\hline 25 & & 5 & 0.9 & 1 & 1.4 & 1.6 & 11.447 & 0.9459 & 1.560 \\
\hline 26 & Step 6 & 1 & 0.95 & 1 & 1.5 & 1.6 & 11.470 & 0.9814 & 1.513 \\
\hline 27 & & 2 & 0.95 & 1 & 1.5 & 1.6 & 11.462 & 0.9650 & 1.535 \\
\hline 28 & & 3 & 0.95 & 1 & 1.5 & 1.6 & 11.452 & 0.9698 & 1.522 \\
\hline 29 & & 4 & 0.95 & 1 & 1.5 & 1.6 & 11.452 & 0.9413 & 1.553 \\
\hline 30 & & 5 & 0.95 & 1 & 1.5 & 1.6 & 11.455 & 0.9666 & 1.529 \\
\hline 31 & Step 7 & 1 & 0.95 & 0.98 & 1.52 & 1.54 & 11.479 & 0.9798 & 1.520 \\
\hline 32 & & 2 & 0.95 & 0.98 & 1.52 & 1.54 & 11.477 & 0.9789 & 1.521 \\
\hline 33 & & 3 & 0.95 & 0.98 & 1.52 & 1.54 & 11.493 & 0.9718 & 1.541 \\
\hline 34 & & 4 & 0.95 & 0.98 & 1.52 & 1.54 & 11.483 & 0.9722 & 1.535 \\
\hline 35 & & 5 & 0.95 & 0.98 & 1.52 & 1.54 & 11.479 & 0.9746 & 1.529 \\
\hline 36 & Step 8 & 1 & 0.96 & 0.98 & 1.53 & 1.54 & 11.494 & 0.9782 & 1.531 \\
\hline 37 & & 2 & 0.96 & 0.98 & 1.53 & 1.54 & 11.490 & 0.9740 & 1.535 \\
\hline 38 & & 3 & 0.96 & 0.98 & 1.53 & 1.54 & 11.477 & 0.9725 & 1.531 \\
\hline 39 & & 4 & 0.96 & 0.98 & 1.53 & 1.54 & 11.488 & 0.9767 & 1.530 \\
\hline 40 & & 5 & 0.96 & 0.98 & 1.53 & 1.54 & 11.486 & 0.9754 & 1.531 \\
\hline
\end{tabular}




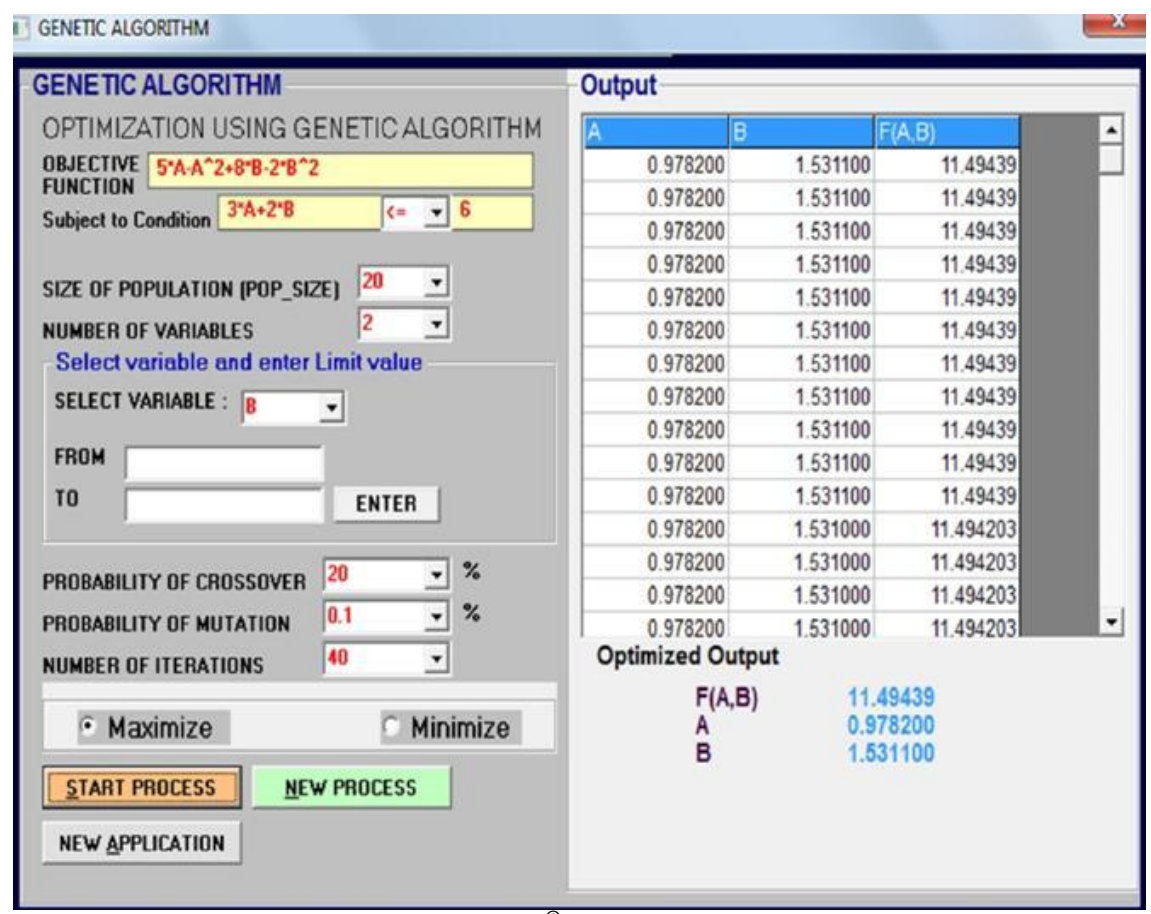

Fig 5: Snapshot of elite-GA ${ }^{\Theta}$ in run mode for function 3.1.2

Table 8 gives the details of the best values of the objective function obtained for consecutive 40 run of GA with similar parameters without stepwise approach.

Table 8. Details of best values of objective function obtained for 40 consecutive run without stepwise approach

\begin{tabular}{cccccc}
\hline Sr. No & Run & $\mathbf{f}\left(\mathbf{x}_{\mathbf{1}}, \mathbf{x}_{\mathbf{2}}\right)$ & Sr. No. & Run & $\mathbf{f}\left(\mathbf{x}_{\mathbf{1}}, \mathbf{x}_{\mathbf{2}}\right)$ \\
\hline 1 & 1 & 8.421 & 21 & 21 & 10.103 \\
2 & 2 & 8.769 & 22 & 22 & 8.190 \\
3 & 3 & 6.734 & 23 & 23 & 8.882 \\
4 & 4 & 11.105 & 24 & 24 & 11.037 \\
5 & 5 & 8.554 & 25 & 25 & 10.571 \\
6 & 6 & 9.991 & 26 & 26 & 7.818 \\
7 & 7 & 8.529 & 27 & 27 & 9.964 \\
8 & 8 & 10.288 & 28 & 28 & 10.673 \\
9 & 9 & 6.237 & 29 & 29 & 11.333 \\
10 & 10 & 9.688 & 30 & 30 & 9.552 \\
11 & 11 & 9.735 & 31 & 31 & 11.224 \\
12 & 12 & 5.948 & 32 & 32 & 5.434 \\
13 & 13 & 9.886 & 33 & 33 & 9.857 \\
14 & 14 & 9.837 & 34 & 34 & 8.598 \\
15 & 15 & 9.691 & 35 & 35 & 10.350 \\
16 & 16 & 10.936 & 36 & 36 & 9.835 \\
17 & 17 & 9.561 & 37 & 37 & 8.488 \\
18 & 18 & 10.382 & 38 & 38 & 8.211 \\
19 & 19 & 10.156 & 39 & 39 & 10.341 \\
20 & 20 & 8.860 & 40 & 40 & $\mathbf{1 1 . 4 4 7}$ \\
\hline
\end{tabular}

Figs. $6 \& 7$ show the graphs plotted between the best values of the objective function for 40 run of elite-GA ${ }^{\odot}$ with \& without stepwise approach respectively.

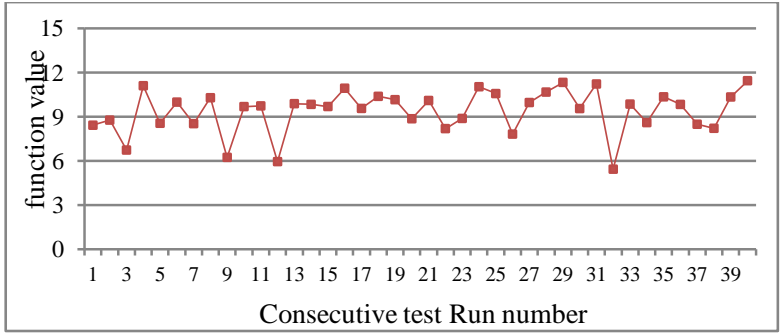

Fig 6: Values of objective function for 40 consecutive run without step wise approach

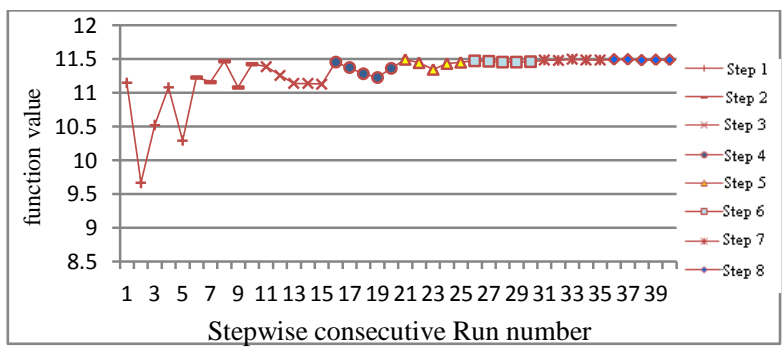

Fig 7: Values of objective function for five consecutive run for each step with stepwise approach

As can be seen from these graphs the stepwise approach in search interval selection results in directing the search towards optimal value more deterministically in this case also.

\subsubsection{Results and Discussion}

Frank-Wolfe algorithm is used as a conventional method for optimizing the given nonlinear objective function 3.1.2. This method is very extensive and time consuming. A large number of iterations are required to reach the optimum solution, \& if done manually, would prove to be tedious method. 
The comparison of the maximum values of the objective function as obtained by Frank-Wolfe algorithm \& GA is given in table $9 \&$ is depicted in Fig. 8. As can be seen from the bar graphics that, GA global optimal value is better than obtained by other methods including Frank-Wolfe algorithm \& also with GA without stepwise approach. The \% improvement over the conventional technique is $13.99 \%$ hence the GA solution with stepwise approach is acceptable.

Table 9. Comparison of Frank-Wolfe algorithm with GA

\begin{tabular}{|c|c|c|c|}
\hline $\begin{array}{l}\text { Maximum } \\
\text { value of } \\
\text { function }\end{array}$ & $\begin{array}{c}\text { Frank- } \\
\text { Wolfe } \\
\text { Algorithm }\end{array}$ & $\begin{array}{l}\text { GA With } \\
\text { stepwise } \\
\text { approach }\end{array}$ & $\begin{array}{l}\text { GA without } \\
\text { stepwise } \\
\text { approach }\end{array}$ \\
\hline $\mathrm{f}\left(\mathrm{x}_{1}, \mathrm{x}_{2}\right)$ & 10.083 & 11.494 & 11.447 \\
\hline \multicolumn{4}{|c|}{ Search variables: } \\
\hline $\mathrm{x}_{1}$ & 0.8333 & 0.978 & 1.025 \\
\hline $\mathrm{x}_{2}$ & 1.1666 & 1.531 & 1.439 \\
\hline
\end{tabular}

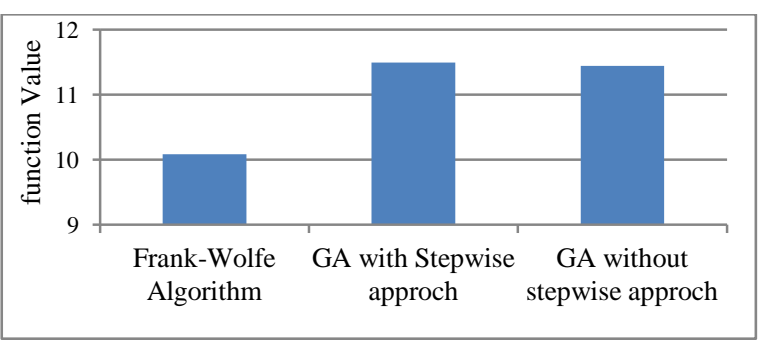

Fig 8; Comparison between values of function 3.1.2 for conventional and GA method

\subsection{Non-linear objective function with non- linear inequality constraints}

3.2.1 Function:

Maximize $\mathrm{f}\left(\mathrm{x}_{1}, \mathrm{x}_{2}\right)=\mathrm{x}_{1} \mathrm{x}_{2}$

Subject to $\mathrm{x}_{1}^{2}+\mathrm{x}_{2} \leq 3$

$$
\begin{aligned}
& 0 \leq x_{1} \leq 1 \\
& 0 \leq x_{2} \leq 2
\end{aligned}
$$

Conventional technique

The objective function has been solved by Sequential Unconstrained Minimization Technique (SUMT). The details are reported in the literature[2].

\section{Genetic Algorithm technique}

The present work optimizes the function 3.2.1 in stepwise manner and using elite-GA ${ }^{\odot}$. The snapshot of elite-GA ${ }^{\odot}$ in run mode for function 3.2.1 is shown in Fig. 9.

Table 10 gives the details of the best values of the function

with the corresponding values of the search variables obtained during consecutive five test run. Based on the values of the objective function obtained the search interval range for the variables is set for carrying out the step 1 run. The values of the search variables set $\&$ the best values of the function obtained during the five consecutive run of step 1-6 are listed in table 11.

\begin{tabular}{|c|c|c|c|c|c|c|c|}
\hline \multirow[b]{2}{*}{ Run } & \multicolumn{2}{|c|}{ Limits of $x_{1}$} & \multicolumn{2}{|c|}{ Limits of $x_{2}$} & \multirow[t]{2}{*}{ Best $\mathbf{f}\left(\mathbf{x}_{1}, \mathbf{x}_{2}\right)$} & \multirow{2}{*}{\multicolumn{2}{|c|}{$\frac{\mathbf{x}_{1} \quad \mathbf{x}_{2}}{\text { Best value }}$}} \\
\hline & Lower & Upper & Lower & Upper & & & \\
\hline 1 & 0 & 1 & 0 & 2 & 0.757 & 0.574 & 1.317 \\
\hline 2 & 0 & 1 & 0 & 2 & 0.537 & 0.496 & 1.083 \\
\hline 3 & 0 & 1 & 0 & 2 & 1.825 & 0.924 & 1.974 \\
\hline 4 & 0 & 1 & 0 & 2 & 1.054 & 0.554 & 1.904 \\
\hline 5 & 0 & 1 & 0 & 2 & 0.434 & 0.343 & 1.265 \\
\hline
\end{tabular}

Table 10. Details of elite-GA ${ }^{\odot}$ Test run for function 3.2.1

\begin{tabular}{|c|c|c|c|c|c|c|c|c|c|}
\hline \multirow[t]{2}{*}{ Sr. No. } & \multirow[t]{2}{*}{ Steps } & \multirow[t]{2}{*}{ Run } & \multicolumn{2}{|c|}{ Limits of $x_{1}$} & \multicolumn{2}{|c|}{ Limits of $x_{2}$} & \multirow{3}{*}{$\begin{array}{c}\begin{array}{c}\text { Best } \\
\mathbf{f}\left(\mathbf{x}_{\mathbf{1}}, \mathbf{x}_{\mathbf{2}}\right)\end{array} \\
1.600\end{array}$} & \multirow{2}{*}{\multicolumn{2}{|c|}{$\frac{x_{1}}{\text { Best value }}$}} \\
\hline & & & Lower & Upper & Lower & Upper & & & \\
\hline 1 & Step 1 & 1 & 0.5 & 1 & 1.5 & 2 & & 0.843 & 1.897 \\
\hline 2 & & 2 & 0.5 & 1 & 1.5 & 2 & 1.590 & 0.964 & 1.648 \\
\hline 3 & & 3 & 0.5 & 1 & 1.5 & 2 & 1.298 & 0.793 & 1.636 \\
\hline 4 & & 4 & 0.5 & 1 & 1.5 & 2 & 1.677 & 0.900 & 1.863 \\
\hline 5 & & 5 & 0.5 & 1 & 1.5 & 2 & 1.884 & 0.996 & 1.891 \\
\hline 6 & Step 2 & 1 & 0.8 & 1 & 1.85 & 2 & 1.950 & 0.988 & 1.973 \\
\hline 7 & & 2 & 0.8 & 1 & 1.85 & 2 & 1.860 & 0.940 & 1.978 \\
\hline 8 & & 3 & 0.8 & 1 & 1.85 & 2 & 1.929 & 0.988 & 1.951 \\
\hline 9 & & 4 & 0.8 & 1 & 1.85 & 2 & 1.841 & 0.926 & 1.988 \\
\hline 10 & & 5 & 0.8 & 1 & 1.85 & 2 & 1.963 & 0.989 & 1.985 \\
\hline 11 & Step 3 & 1 & 0.9 & 1 & 1.9 & 2 & 1.937 & 0.976 & 1.983 \\
\hline 12 & & 2 & 0.9 & 1 & 1.9 & 2 & 1.973 & 0.994 & 1.983 \\
\hline 13 & & 3 & 0.9 & 1 & 1.9 & 2 & 1.965 & 0.986 & 1.991 \\
\hline 14 & & 4 & 0.9 & 1 & 1.9 & 2 & 1.943 & 0.989 & 1.963 \\
\hline 15 & & 5 & 0.9 & 1 & 1.9 & 2 & 1.862 & 0.975 & 1.910 \\
\hline 16 & Step 4 & 1 & 0.95 & 1 & 1.95 & 2 & 1.964 & 0.991 & 1.981 \\
\hline 17 & & 2 & 0.95 & 1 & 1.95 & 2 & 1.964 & 0.987 & 1.989 \\
\hline 18 & & 3 & 0.95 & 1 & 1.95 & 2 & 1.939 & 0.988 & 1.961 \\
\hline 19 & & 4 & 0.95 & 1 & 1.95 & 2 & 1.974 & 0.998 & 1.977 \\
\hline 20 & & 5 & 0.95 & 1 & 1.95 & 2 & 1.979 & 0.998 & 1.982 \\
\hline
\end{tabular}

Table 11. Search interval set for variables $\&$ best values obtained for consecutive five run for step 1 to 6 


\begin{tabular}{llllllllll}
\hline 21 & Step 5 & 1 & 0.98 & 1 & 1.97 & 2 & 1.989 & 0.999 & 1.990 \\
22 & & 2 & 0.98 & 1 & 1.97 & 2 & 1.986 & 0.996 & 1.993 \\
23 & & 3 & 0.98 & 1 & 1.97 & 2 & 1.996 & 0.998 & 2.000 \\
24 & & 4 & 0.98 & 1 & 1.97 & 2 & 1.982 & 0.995 & 1.990 \\
25 & & 5 & 0.98 & 1 & 1.97 & 2 & 1.982 & 0.995 & 1.992 \\
\hline 26 & Step 6 & 1 & 0.99 & 1 & 1.99 & 2 & 1.998 & 0.999 & 1.998 \\
27 & & 2 & 0.99 & 1 & 1.99 & 2 & $\mathbf{1 . 9 9 9}$ & 0.999 & 1.999 \\
28 & & 3 & 0.99 & 1 & 1.99 & 2 & 1.985 & 0.996 & 1.992 \\
29 & & 4 & 0.99 & 1 & 1.99 & 2 & 1.992 & 0.998 & 1.996 \\
30 & & 5 & 0.99 & 1 & 1.99 & 2 & 1.995 & 0.999 & 1.996 \\
\hline
\end{tabular}

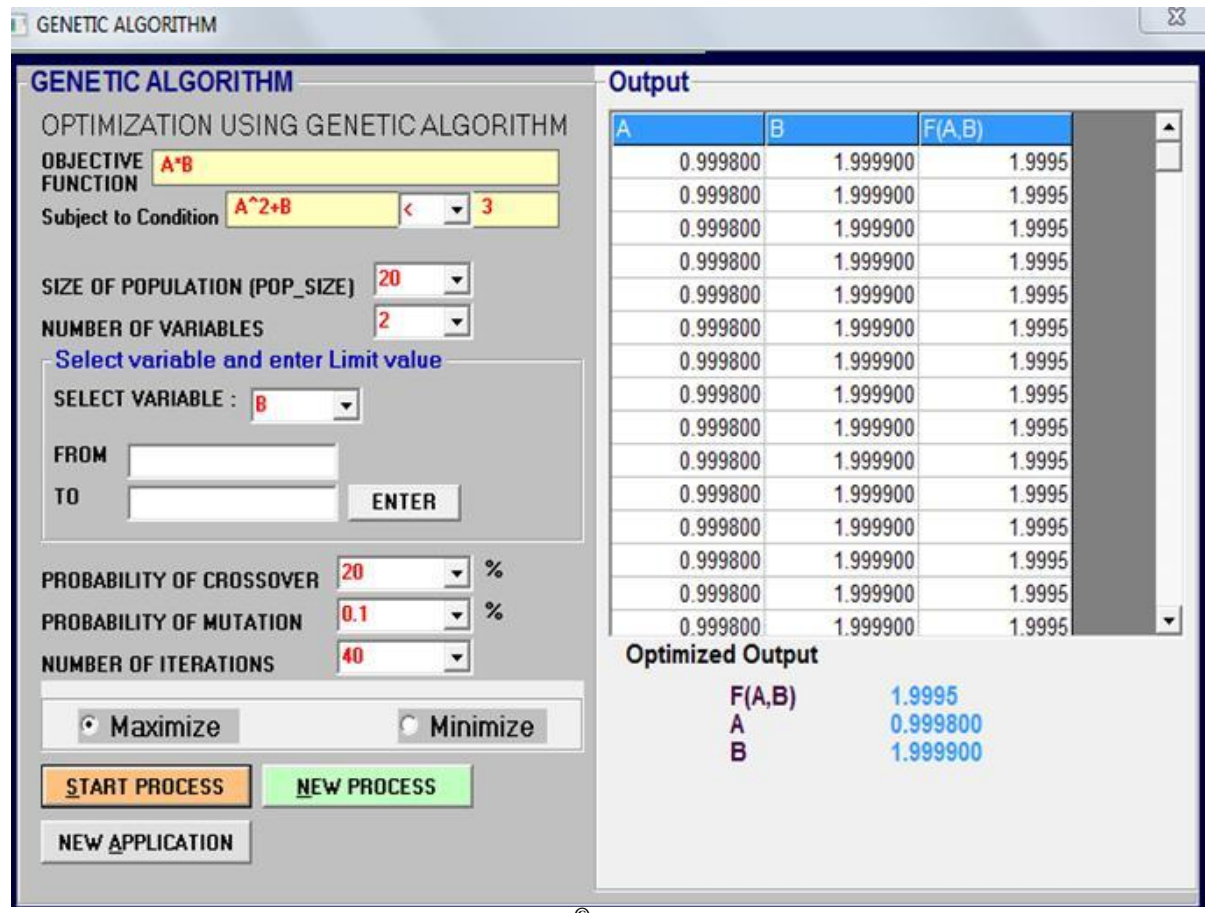

Fig 9: Snapshot of elite-GA ${ }^{\odot}$ in run mode for function 3.2.1

Table 12 gives the details of the best values of the objective function 3.2.1 obtained for consecutive 30 run of GA with similar parameters without stepwise approach.

Table 12. Details of best values of objective function obtained for 25 consecutive run without step wise approach

\begin{tabular}{cccccc}
\hline $\begin{array}{c}\text { Sr. } \\
\text { No. }\end{array}$ & Run & $\mathbf{f}\left(\mathbf{x}_{\mathbf{1}}, \mathbf{x}_{\mathbf{2}}\right)$ & $\begin{array}{c}\text { Sr. } \\
\text { No. }\end{array}$ & Run & $\mathbf{f}\left(\mathbf{x}_{\mathbf{1}}, \mathbf{x}_{\mathbf{2}}\right)$ \\
\hline 1 & 1 & 0.757 & 16 & 16 & 1.193 \\
2 & 2 & 0.537 & 17 & 17 & 1.019 \\
3 & 3 & 1.825 & 18 & 18 & 0.305 \\
4 & 4 & 1.054 & 19 & 19 & 0.984 \\
5 & 5 & 0.434 & 20 & 20 & 1.262 \\
6 & 6 & 0.548 & 21 & 21 & 0.986 \\
7 & 7 & 0.328 & 22 & 22 & 0.196 \\
8 & 8 & 1.722 & 23 & 23 & 0.830 \\
9 & 9 & 1.732 & 24 & 24 & 0.451 \\
10 & 10 & $\mathbf{1 . 8 9 2}$ & 25 & 25 & 1.655 \\
11 & 11 & 1.179 & 26 & 26 & 0.380 \\
12 & 12 & 1.361 & 27 & 27 & 0.885 \\
13 & 13 & 0.814 & 28 & 28 & 0.907 \\
14 & 14 & 1.167 & 29 & 29 & 1.725 \\
15 & 15 & 0.815 & 30 & 30 & 0.198 \\
\hline
\end{tabular}

Figs. $10 \& 11$ show the graphs plotted between the best value of function 3.2.1 obtained for 30 run of elite-GA ${ }^{\odot}$ with \& without stepwise approach respectively.

As can be seen from the nature of these graphs the stepwise approach in search interval selection results in directing the search towards optimal value more deterministically.

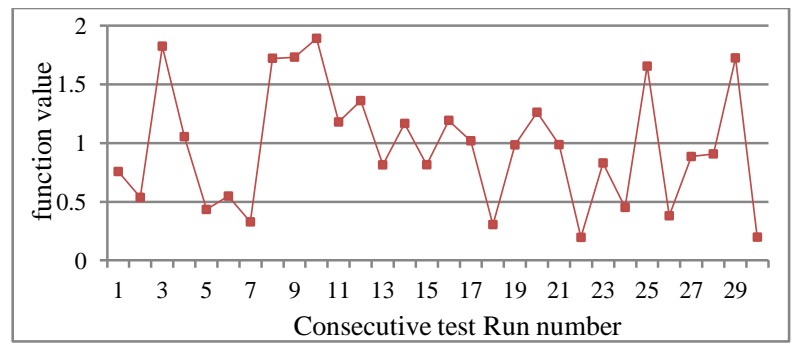

Fig 10: Values of objective function for 30 consecutive run without step wise approach 


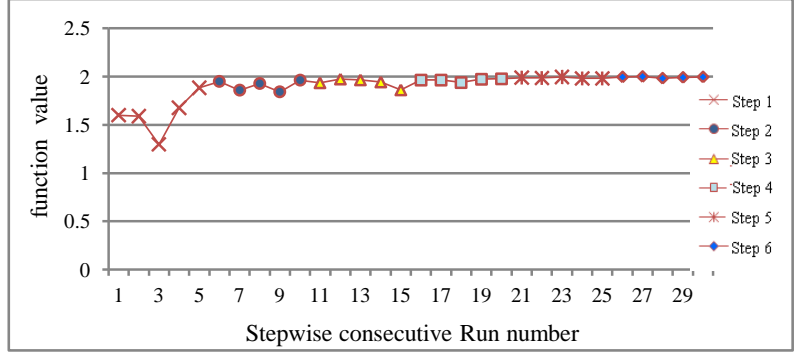

Fig 11: Values of objective function for five consecutive run for each step with stepwise approach

\subsubsection{Results and Discussion}

The objective function 3.2.1 discussed in this part of the present work has been solved by SUMT. Table 13 gives the comparison between the maximum values of the objective function as obtained using SUMT \& GA with and without stepwise approach \& the Fig. 12 depicts same graphically. It can be seen the table that the best global maximum value obtained \& the percentage improvement is of the order of $0.45 \%$ over the next global value obtained using SUMT. It can be said that the GA with stepwise approach solution is acceptable.

Table 13. Comparison of optimum results obtained by using Sequential Unconstrained Minimization Technique and GAs

\begin{tabular}{|c|c|c|c|}
\hline $\begin{array}{c}\text { Maximum } \\
\text { value of } \\
\text { function }\end{array}$ & SUMT & $\begin{array}{c}\text { GA With } \\
\text { stepwise } \\
\text { approach }\end{array}$ & $\begin{array}{l}\text { GA without } \\
\text { stepwise } \\
\text { approach }\end{array}$ \\
\hline $\mathrm{f}\left(\mathrm{x}_{1}, \mathrm{x}_{2}\right)$ & 1.990 & 1.999 & 1.892 \\
\hline \multicolumn{4}{|c|}{ Search variables: } \\
\hline $\mathrm{x}_{1}$ & 0.998 & 0.999 & 0.9662 \\
\hline $\mathrm{x}_{2}$ & 1.994 & 1.999 & 1.9583 \\
\hline
\end{tabular}

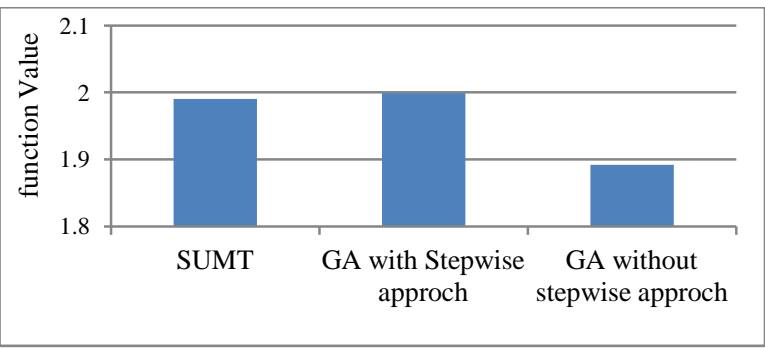

Fig 12: Comparison between values of function 3.2.1 for conventional and GA method

\section{CONCLUSION}

Genetic algorithm is a random search method with universality of approach in providing optimization solutions. One of the factors that limit the applicability of GA is in its uncertainty to reach optimal solution. Although several conventional optimization techniques have been reported in the literature, most of these techniques are problem specific \& selective in nature. The present work has addressed to these limitation of conventional and GA technique \& suggested novel stepwise approach in search interval selection of variables. Among the three non-linear optimization problems that are selected for numerical experimentation, two involved linear inequality constraint whereas the remaining has the non-linear inequality constraint. These are reported in literature \& solved using Penalty function, Frank-Wolfe algorithm \& Sequential unconstrained minimization technique respectively. The limitations of these methods are overcome by using GA with stepwise search interval selection approach. Based on the comparison between the best optimal values using GA with and without step wise approach \& the conventional techniques, it can be concluded that the present work has successfully highlighted the utility of the novel approach to GA in providing better optimal solution to test optimization problems.

The present work is demonstrative \& it is felt necessary to substantiate the claim by extending this stepwise search interval approach of GA in selection of variables to other problems of optimization.

\section{ACKNOWLEDGEMENT}

Authors are thankful to Director, Laxminarayan Institute of Technology, Nagpur for the facilities provided.

\section{REFERENCES}

[1] Edgar T.F. and Himmelblau D.M., Optimization and Chemical Processes, McGraw Hill Publication Co; 1989.

[2] Hillier F., Lieberman G., Introduction to Operations Research, McGraw-Hill Co., New York, 2001

[3] Rao S.S., Engineering optimization Theory and practice, Third Edition New age international publishers, 2013

[4] Goldberg D.E., Genetic Algorithms in Search, Optimization and Machine Learning, Addison-Wesley Publication Company; 1989.

[5] Migdalas A., Toraldo G., Kumar V., Nonlinear optimization and parallel computing, Parallel Computing 29 (2003) 375-391

[6] Tang K., Sun T., Yang Jg-Yu, An improved genetic algorithm based on a novel selection strategy for nonlinear programming problems, Computers and Chemical Engineering 35 (2011) 615-621

[7] Aryanezhad M.B., Hemati M., A new genetic algorithm for solving nonconvex nonlinear programming problems, Applied Mathematics and Computation 199 (2008) 186194

[8] Giuggioli Busacca P., Marseguerra M., Zio E., Multiobjective optimization by genetic algorithms: application to safety systems, Reliability Engineering and System Safety 72 (2001) 59-74

[9] Konak A., Coit D.W., Smith A.E., Multi-objective optimization using genetic algorithms: A tutorial, Reliability Engineering and System Safety 91 (2006) 992-1007

[10] Toksar M.D., Güner E., Solving the unconstrained optimization problem by a variable neighborhood search, J. Math. Anal. Appl. 328 (2007) 1178-1187

[11] Reese A., Random number generators in genetic algorithms for unconstrained and constrained optimization, Nonlinear Analysis 71 (2009) e679-e692

[12] Bunnag D., Sun M., Genetic algorithm for constrained global optimization in continuous variables, Applied Mathematics and Computation 171 (2005) 604-636 
[13] Xiang Li, Gang Du, Inequality constraint handling in genetic algorithms using a boundary simulation method, Computers \& Operations Research 39 (2012) 521-540

[14] Tsoulos I.G., Solving constrained optimization problems using a novel genetic algorithm, Applied Mathematics and Computation 208 (2009) 273-283

[15] Martorell S., Carlos S., Sánchez A., Serradell V., Constrained optimization of test intervals using a steadystate genetic algorithm, Reliability Engineering and System Safety 67 (2000) 215-232

[16] Summanwar V.S., Jayaraman V.K., Kulkarni B.D., Kusumakar H.S., Gupta K., Rajesh J., Solution of constrained optimization problems by multi-objective genetic algorithm, Computers and Chemical Engineering 26 (2002) 1481-1492

[17] Guan J., Aral M.M., Progressive genetic algorithm for solution of optimization problems with nonlinear equality and inequality constraints, Applied Mathematical Modelling 23 (1999) 329-343

[18] Xie G.N., Sunden B., Wang Q.W., Optimization of compact heat exchangers by a genetic algorithm, Applied Thermal Engineering 28 (2008) 895-906

[19] Pandharipande S.L., Satai S.I., Genetic algorithm: For optimization of liquid extraction column flow rates, Chemical Engineering World (2006) 53-57

[20] Pandharipande S.L., Satai S.I., Genetic Algorithm: An Evolutionary Algorithm for Chemical Engineering Economics, Chemical Engineering World (2007) 30-40

[21] Sarkar D., Modak J.M., Optimisation of fed-batch bioreactors using genetic algorithms, Chemical Engineering Science 58 (2003) 2283-2296

[22] El-Mahdy O., Ahmed M., Metwalli S., Computer aided optimization of natural gas pipe networks using genetic algorithm, Applied Soft Computing 10 (2010) 1141-1150
[23] Hasni A., Taibi R., Draoui B., Boulard T., Optimization of Greenhouse Climate Model Parameters Using Particle Swarm Optimization and Genetic Algorithms, Energy Procedia 6 (2011) 371-380

[24] Pandharipande S.L., Artificial Neural Networks: FFEBPN With Software, Central Techno Publishers; Nagpur; June 2008

[25] Gilberto A.S. Segundo, Renato A. Krohling, Rodrigo C. Cosme, A differential evolution approach for solving constrained min-max optimization problems, Expert Systems with Applications 39 (2012) 13440-13450

[26] Li-ning X., Ying-wu C., Huai-ping C., An intelligent genetic algorithm designed for global optimization of multi-minima functions, Applied Mathematics and Computation 178 (2006) 355-371

[27] Mohamed A.W., Sabry H.Z., Constrained optimization based on modified differential evolution algorithm, Information Sciences 194 (2012) 171-208

[28] Shopova E.G., Vaklieva-Bancheva N.G., BASIC-A genetic algorithm for engineering problems solution, Computers and Chemical Engineering 30 (2006) 12931309

[29] Elsayed S.M., Sarker R.A., Essam D.L., Multi-operator based evolutionary algorithms for solving constrained optimization problems, Computers \& Operations Research 38 (2011) 1877-1896

[30] Cos kun Hamzac,ebi, Improving genetic algorithms' performance by local search for continuous function optimization, Applied Mathematics and Computation 196 (2008) 309-317

[31] Pandharipande S.L., Satai S.I., elite-GA ${ }^{\oplus}, \quad$ SW$3359 / 2007$

[32] Bradley S., Hax A., Magnanti T., Applied Mathematical Programming, Addison-Wesley 1977 